\title{
Biomedical research workforce summit makes strides in implementing change for postdocs
}

\author{
Viviane Callier \\ Experts from industry and academia have begun the process of putting the biomedical research enterprise \\ on a more sustainable path.
}

$\mathrm{n}$ the last three years, more than nine reports have been published with recommendations of how to put the biomedical research enterprise on a more sustainable path. A recent analysis (PNAS 112, 10832-10836, 2015) synthesized the consensus recommendations, and on February 4 and 5, 2016, a group of approximately 30 experts from universities, scientific societies, industry, nonprofits and government agencies gathered to define and take the first steps in implementing these recommendations.

"We saw group after group come out with lists of recommendations for change, but little in the way of action items," said lead author Chris Pickett, at the time a policy analyst at the American Society for Biochemistry and Molecular Biology (ASBMB) and now director of Rescuing Biomedical Research. "The message of our paper was-these are the recommendations a majority of the community has gotten behind, so now let's begin implementation." The goal of the summit, organized by ASBMB, was to define clear action items to move forward on three consensus recommendations: increasing the number of and roles for staff scientists; optimizing the workforce by harmonizing the various designations for postdocs and identifying mechanisms to ensure equal pay and benefits; and enhancing training by developing an online resource of training materials to help universities provide their postdocs with better career development opportunities.

\section{Staff scientists}

Bob Matthews, Arthur F. and Helen P. Koskinas Professor of Biochemistry and

Viviane Callier is at the Ronin Institute,

Montclair, New Jersey, USA.

e-mail:vcallier@gmail.com
Molecular Pharmacology at the University of Massachusetts Medical School in Worcester, and Kay Lund, director of the Division of Biomedical Research Workforce in the Office of the Director at the US National Institutes of Health (NIH), led the discussion by first stating the obvious-the current system, primarily staffed by postdocs and graduate students whose training periods have gotten longer because academic positions are few and far between, is not sustainable. They proposed to rebalance the workforce by integrating more staff scientists into the workforce.

Shirley Tilghman, former president of Princeton University, pointed out that there are actually several flavors of staff scientists, and some might be an easier sell than others. For example, core facilities, which provide equipment and expertise not available within individual laboratories, are often run by staff scientists. These scientists play an important role in the research community and it would not be difficult to convince researchers of the need for these positions; furthermore, these roles are not typically filled by trainees.

However, it would be a harder sell to replace graduate students and postdocs with staff scientists, she said, because there are currently no data on the cost-effectiveness and productivity of staff scientists compared to trainees. Given that staff scientists are more expensive than trainees, principal investigators (PIs) may be reluctant to hire them. In addition, "the staff scientist position is only as stable as your grant," pointed out Jeremy Berg, professor and associate vice chancellor of science strategy and planning at the University of Pittsburgh, so there needs to be a mechanism to provide a little more stability for a staff scientist position.

Alan Leshner, CEO emeritus of the American Association for the Advancement of Science, also pointed to a possible cultural issue by asking, "Why would anybody want to be a staff scientist? There has to be some kind of cultural shift that says 'you're not a loser," he emphasized. People need to see the staff scientist as a position where they can grow in their careers.

Because Congress has already, through the omnibus bill, charged the National Academies with conducting a comprehensive study on policies affecting the next generation of scientists, the group decided that it would be important for the study to include an analysis of the costeffectiveness and productivity of staff scientists. Bruce Alberts, Chancellor's Leadership Chair in Biochemistry and Biophysics for Science and Education at the University of California, San Francisco, agreed to lobby the National Academy of Sciences and make the case for including staff scientists in this analysis.

The group also recommended that the NIH require all staff scientists supported by NIH grants to complete individual development plans every year. Such plans are currently recommended for graduate students and postdocs, and the group agreed-in spite of concerns about the additional reporting burden-that staff scientists should begin using this framework for their career development, too.

\section{Postdocs}

The discussion on postdocs, led by Gary McDowell, a postdoctoral scholar at Tufts University and co-chair of Future of Research, focused on harmonizing the various designations for postdocs, which often have implications for salary and/or stipend and benefits. The various designations come from the complicated dual status of postdocs as both employees and trainees; the proliferation of titles is largely driven by human resources departments (HR). 
The plethora of designations makes inequality of salary and benefits rife among postdocs (even at the same institution), and postdocs who change status when they win a prestigious fellowship might lose their benefits (e.g., health insurance and unemployment insurance) through the university. The various designations also make it almost impossible for a government agency like NIH to keep track of how many postdocs it is funding and where they end up after their training.

"The postdoc is such an impossible position from an institutional point of view," said Tilghman. "An institution does not view postdocs as their employees, so they really don't care. The department doesn't care, because the department didn't hire the postdoc. The only person who has any stake in it is the PI, and the PI is often very conflicted. So it's really a tough one to figure out."

In spite of these challenges, McDowell cited the example of success at Tufts and the DanaFarber Cancer Institute, which managed to harmonize postdoc designations and benefits after the postdocs pushed for them. The urgency for this change came from the fact that postdocs were threatening to unionize if these changes were not made. The success was dependent on these institutions' ability to provide a pot of money to equalize the pay and benefits for all postdocs regardless of their source of funding. The fact that this change was successful suggests that other institutions could learn from this model and equally make the change. McDowell will lead a team to create a step-by-step guide for institutions on how to harmonize postdoc designations from an HR perspective so that other institutions can follow suit.

\section{Enhancing training}

Designations aside, the issue of postdoc training remains a major concern: provision of training is patchy across institutions, and postdocs receive little training for any positioneven academic ones, said McDowell. Postdocs, for example, are rarely taught how to manage people and budgets-key skills for principal investigators.

McDowell argued in favor of the 5-year term limit for postdocs-a guideline that is intended to emphasize that the postdoc is a transient training position and to alleviate the "glut" of postdoctoral researchers that continues to swell. The term limits can be unnecessarily strict, however, and can be evaded by using different HR codes, so it is difficult to enforce. The 5 -year term limit addresses only a symptom, not an underlying cause, cautioned Tilghman.

The larger issue is to change the culture about the purpose of a postdoc. Currently, postdoctoral training is the default choice for many
$\mathrm{PhD}$ graduates. But "the postdoc is a defined, temporary period of mentored advanced training in research," said Gregory Petsko, Arthur J. Mahon Professor of Neuroscience at Weill Cornell Medical College. "There's a huge disconnect between how the PI typically sees the postdoc and how the postdoc sees the postdoc," he explained. "The postdoc usually views it as a training period, but the PI views it as essentially indentured servitude. This is a problem."

Most nonresearch careers do not require a postdoc, but the reason that many $\mathrm{PhD}$ graduates go into postdoc positions is that "there is a huge conflict of interest for the faculty member," explained Berg. The postdoc's "main function is to keep the professor funded and famous," but the postdoc doesn't have great career prospects afterwards. "I was a little bit shocked when people were resisting the idea that we should not train as many PhDs as we possibly can," said Berg. There is a huge opportunity cost for postdocs who train in the laboratory for many years only to go do something that does not utilize their training, he said.

Phil Ryan, director of student services at the Office of Intramural Training and Education at NIH, pointed out that "the main problem is, you can give graduates an idea of what they might want to do, but you can't get a job with an idea of what you want to do. You need experience." Experience can be gained only if graduate training is restructured to incorporate more internships and similar work experiences, he argued. Although workshops for transferable skills can be useful, "most postdocs have no experience that makes them hirable for their first job outside of the lab," he said.

To address these shortcomings in postdoc training, the group proposed creating an online center or repository of career development resources, trainings, lesson plans and materials that could be used by career development offices in universities across the country to better equip their postdocs to succeed on the job market. The center would serve as a national dissemination hub, said Alberts, and would include not only resources and guidelines for institutional best practices, but also a list of certified training advisors and ambassadors who could conduct outreach and education about postdoc training at institutions across the country.

The online repository would be carefully curated, and the material would undergo a peer-review process before being posted online, explained Cynthia Furhmann, assistant dean of career and professional development at the University of Massachusetts Medical School, who spearheaded this effort. The intended audience is not so much the postdocs themselves, but rather the faculty and career development professionals at universities who seek to help postdocs develop their career paths, she said.

Although in principle a good idea-one that the group unanimously agreed should be pursued-there still remains some fleshing out to do. "We need to clarify the customer, the product and the incentive structure," said Kenneth Gibbs, program analyst at the National Institute of General Medical Sciences. A steering committee led by Furhmann will develop these ideas, conduct a needs assessment in the community, further clarify the intended audience(s) for this resource, and develop a mechanism for creating and vetting the materials and the certified training advisors.

\section{Sustainable funding}

Jeremy Berg led the discussion on sustainable funding-beginning with a discussion of what is meant by sustainability. "The consequences of boom-and-bust funding are acutely felt in a system where we have multiyear grants with single-year budget authority," said Howard Garrison, director of public affairs at the Federation of American Societies for Experimental Biology. When funding agencies receive their budget from Congress each year, most of the funds are already spoken for by awards made in previous years, so the funding agencies have very little wiggle room to buffer the variations from year to year, he explained.

Berg, Harrison and others plan to write a short article explaining the consequences of boom-and-bust funding cycles and making the case for sustained, reliable increases in funding from year to year. They will host a congressional briefing on this topic, as well as convene meetings of high-level individuals from academia and industry to better align the academic and industry communities in support of sustainable funding.

\section{Changing culture, from the top}

Although the activities and projects organized by this group are a commendable start to implementing the consensus recommendations, the group wrapped up, realizing how much work remains to be done. And "all of these things are going to be great, but they won't have the impact we want unless we also change the culture," warned Petsko. "Culture change really has to come from the top. We senior scientists have to stop sitting in rooms and judging junior scientists by checking off how many papers they've published in glamour journals. Unless we stop doing things like this as senior scientists, all of this is just going to be hot air," he said.

COMPETING FINANCIAL INTERESTS

The author declares no competing financial interests. 